\title{
Combating aggressive macrophyte encroachment on a typical Yangtze River lake: lessons from a long-term remote sensing study of vegetation
}

\author{
Qiang Jia $\cdot$ Lei Cao $\cdot$ Hervé Yésou $\cdot$ Claire Huber $\cdot$ Anthony David Fox
}

Received: 28 August 2016/Accepted: 5 December 2016/Published online: 19 December 2016

(C) Springer Science+Business Media Dordrecht 2016

\begin{abstract}
Overabundant growth of emergent lacustrine plants can cause biodiversity, ecosystem service and economic loss. The two-basined Wuchang Lake is a typical small shallow lake within the Yangtze River floodplain. Expansion of the emergent macrophyte Zizania latifolia at Wuchang Lower Lake (to $49 \mathrm{~km}^{2}$ in area, c. $87.0 \%$ of Lower Lake) has increasingly denied the local community open water for fishing since the 1980s. To better understand the causes of these changes and potential remediation, we used
\end{abstract}

Handling Editor: Kevin Murphy.

Electronic supplementary material The online version of this article (doi:10.1007/s10452-016-9609-9) contains supplementary material, which is available to authorized users.

Q. Jia

School of Life Sciences, University of Science and Technology of China, 96 JinZhai Road Baohe District, Hefei 230026, Anhui, China

L. Cao $(\bowtie)$

Research Center for Eco-Environmental Sciences, Chinese Academy of Sciences, 18 Shuangqing Road, Haidian District, Beijing 100085, China

e-mail: leicao@rcees.ac.cn

H. Yésou · C. Huber

ICube-SERTIT, Strasbourg University, BP10413, 67412 Illkirch Graffenstaden, France

\section{A. D. Fox}

Department of Bioscience, Aarhus University, Kal $\varnothing$, Grenåvej 14, 8410 Rønde, Denmark annual Landsat imagery from 1975 to 2012 to determine the patterns of expansion between years as well as the effects of water levels in different seasons and trophic status on the annual extent of macrophytes in the Lower Lake. These analyses showed that: (1) $Z$. latifolia progressively covered the Lower Lake, while remaining confined to one inlet in the Upper Lake; (2) despite the generally increasing trend, there were obvious annual variations in area of Z. latifolia; (3) variation of water level in spring contributed to between-year variation in area and was significantly negatively correlated with expansion in Z. latifolia. Based on these results, to reduce the expansion in $Z$. latifolia, we recommend maintaining spring Lower Lake water levels above at least at $11.6 \mathrm{~m}$ and better at $12 \mathrm{~m}$, cutting shoots in June and July, with subsequent shoot removal in autumn.

Keywords Macrophyte control - Management · Trophic status - Water level - Zizania latifolia

\section{Introduction}

Along the middle and lower reaches of Yangtze River floodplain, small shallow lakes (in contrast to larger and highly dynamic water bodies such as Poyang and Dongting Lakes) play an important role in supporting the sustainable development of local communities, contributing ecological services in the form of flood 
control, water storage, irrigation, fisheries, aquaculture and biodiversity conservation (Lei 1999; Barter et al. 2005; Barzen et al. 2009; Cao and Fox 2009; Cao et al. 2010; Harris and Zhuang 2010; Fox et al. 2011). Their smaller size makes such lakes more sensitive to human activities, and since the 1950s, their hydrology and ecosystems have suffered from the effects of water abstraction, dam construction, land claim, nutrient enrichment, intensive aquaculture and climate change. As a result, there have been severe losses to the extent and total number of these lakes, while the remnants suffer continued degradation as a result of contractions in wetland extent, eutrophication and intensive human disturbance (Fang et al. 2006).

Many limnological studies have explored the dynamics of the distribution and abundance of submerged macrophytes, since these plants provide important ecological services, such as sediment stabilisation and reductions in water current dynamics, as well as providing food, shelter and habitats for aquatic organisms (Orth and Moore 1983; Jackson et al. 2001; van der Heide et al. 2011). In some lakes, submerged macrophytes are threatened by the expansion of emergent macrophytes from shorelines, such as that of Zizania latifolia (Griseb.) Turcz. ex Stapf at East Taihu Lake, where the rapid expansion of this species had covered $35.5 \mathrm{~km}^{2}$ of formerly open water (characterised by a previous lack of visible vegetation on the surface) by 1996 (Li 1996). Studies show that such emergent macrophytes can also provide beneficial ecological services, such as prevention of erosion, nutrient absorption and the provision of shelter, habitat and food for organisms such as fish and waterbirds (Kühl and Zemlin 2000; Engloner 2009). On the other hand, overabundant growth of emergent plants, potentially accelerated by human activities (Lampert and Sommer 2007), can cause biodiversity loss and adversely affect the economic potential of the lakes (Rørslett 1991; Andersson 2001; Rannap et al. 2007).

Wuchang Lake $\left(30^{\circ} 17^{\prime} \mathrm{N}, 116^{\circ} 44^{\prime} \mathrm{E}\right)$ is a two-basin lake that is typical of many small shallow lakes along the Yangtze River. The current extent of Wuchang Lake is half that in the 1940 s (c. $290 \mathrm{~km}^{2}$ ), due to extensive land claim and loss of its hydrological continuity with the Yangtze River, the result of a sluice constructed in 1960 (see Fig. 1; Wangjiang County Compilation Committee 1995). Since then, intensive aquaculture has replaced the previous exploitation of natural stocks because of declines in native fish populations. All these changes have had significant impacts on the aquatic system. In recent decades, expansion in the extent of $Z$. latifolia covering Wuchang Lower Lake has caused great anxiety amongst the fishing community for whom up to $49 \mathrm{~km}^{2}$ (c. $87.0 \%$ of Lower Lake) of encroaching $Z$. latifolia, and other emergent macrophytes have increasingly denied them open water for their fishing activities. The Upper Lake (which has experienced the same changes in water quality as the Lower Lake) has retained high fish production and has been unaffected by changes in macrophyte distribution and abundance over the same period. Hydrology, especially waterlevel fluctuations, is a major environmental factor influencing aquatic systems, and many studies have demonstrated correlations between changes in hydrology and aquatic macrophyte abundance (see Scheffer 2004). Other factors, such as trophic status, are also significantly related to succession in aquatic vegetation communities (Malthus et al. 1990; Scheffer et al. 2003; Zhao et al. 2012). Given the differences between the Upper and Lower Wuchang Lakes, we have a unique opportunity to learn from comparing and contrasting the effects of water-level variations and trophic status on macrophyte communities in the two connected basins, with implications for remedial actions and potential reinstatement of open water to Wuchang Lower Lake.

Efforts to understand long-term changes in macrophyte communities in lakes such as those at Wuchang are severely hampered by lack of historical field data (Partanen and Hellsten 2005). In this investigation, we used medium spatial resolution Landsat satellite images (available back to the 1970s) to determine when and how the area of $Z$. latifolia expanded and contracted over this period. Several studies have shown that Landsat images, especially TM images, offer an economical and efficient means to assess the extent of aquatic macrophytes (Brivio et al. 2001; Nelson et al. 2006; Liira et al. 2010; Zhao et al. 2012). In addition, Landsat images can also be used to extract information on trophic status (by offering remotely sensed chlorophyll-a levels and Secchi disc depth) across large temporal and spatial scales (Olmanson et al. 2008; Huang et al. 2014).

In a recently published study, Zhang et al. (2016) suggested a possible correlation between the expansion of Z. latifolia at Wuchang Lake during 1981-2009 and the reduced water level during germination (February 

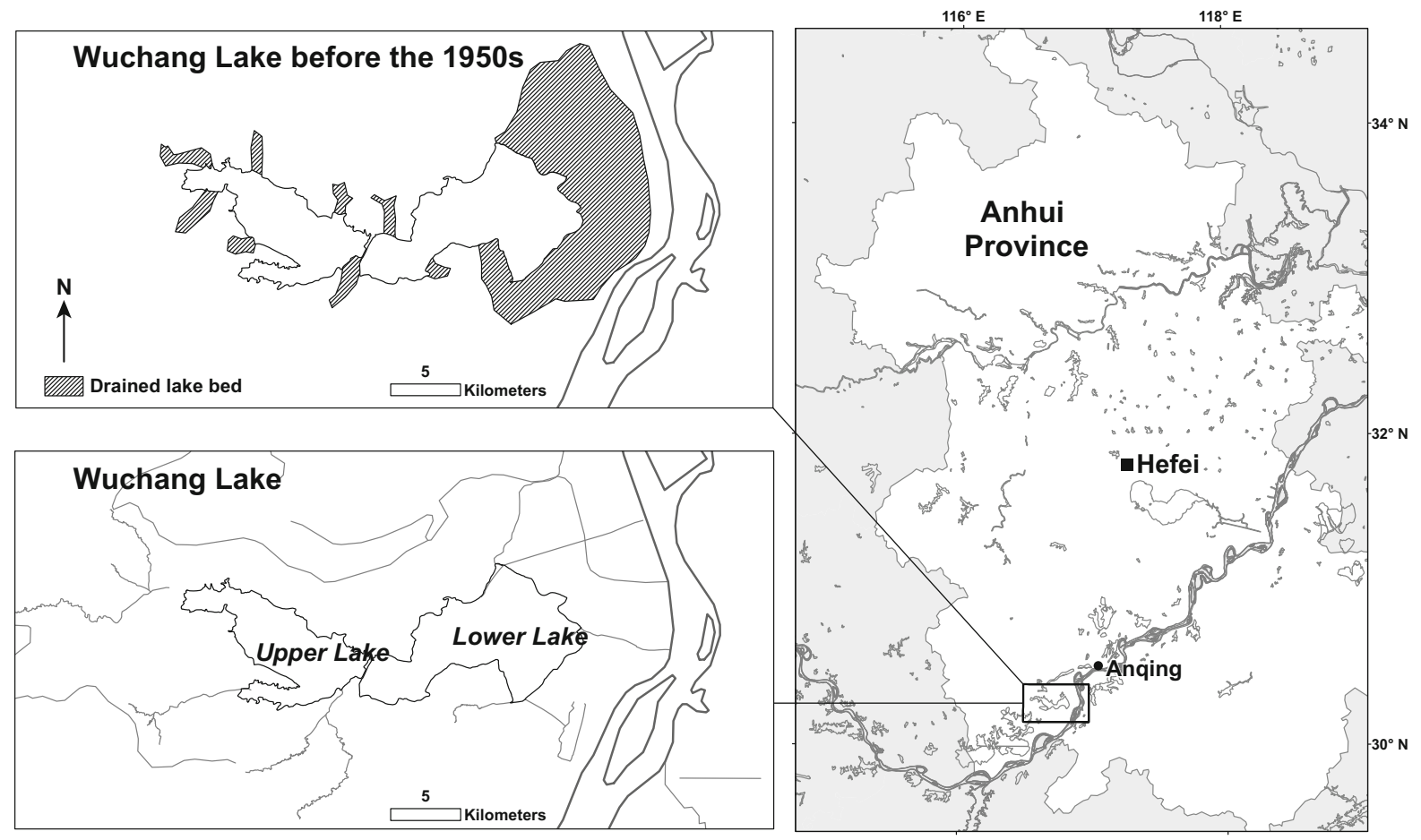

Fig. 1 Location of Wuchang Lake in the Yangtze River Valley in Anhui Province and (inset) its former (pre 1950s, upper) and current (2013, lower) extent of aquatic habitat. The shaded area

to March) after the construction of the Wanhe Sluice in 1959. However, this was based on only 6 years of data, from which they concluded that there had been an annual average growth rate of $1.8 \mathrm{~km}^{2}$ in extent of $Z$. latifolia per annum, but failed to establish any causal link that could explain the changes. In this paper, we use the available Landsat imagery to: (1) reconstruct the annual changes in the nature and extent of vegetation in relation to open water at Wuchang Lake over the period 1975-2012 inclusive, (2) investigate the effects of annual water level and trophic status on the extent of macrophytes in Lower Lake and (3) based on these results, develop strategies for sustainable management in future with the objective of reducing the current extent of Z. latifolia.

\section{Methods}

Study area

Wuchang Lake lies west of Anqing city, in Anhui Province, east central China $\left(30^{\circ} 17^{\prime} \mathrm{N}, 116^{\circ} 44^{\prime} \mathrm{E}\right)$. in the upper map shows the former extent of Wuchang Lakes which were drained for agriculture during the 1950s-1960s

Before the 1950s, the area of Wuchang Lake was much larger than at present (Fig. 1), declining from about 290 to $100 \mathrm{~km}^{2}$ during the $1950 \mathrm{~s}$ and $1960 \mathrm{~s}$ (Wangjiang County Compilation Committee 1995). Wuchang Lake was isolated from the Yangtze River by sluices in 1960, and a dam was built in 1970 to complete the hydrological separation of the lake in the dry season (December to April). The current lake is $25.5 \mathrm{~km}$ long, with an average width of $3.9 \mathrm{~km}$ and an area of $105.3 \mathrm{~km}^{2}$ (Fig. 1). The minimum and maximum lake bed elevation is $8.96 \mathrm{~m}$ above sea level and $12.50 \mathrm{~m}$, averaged $10.60 \mathrm{~m}$, although the lake bed elevation of Upper Lake is on average $90 \mathrm{~cm}$ lower than the Lower Lake. Three major streams contribute most of the inflow into the basins and the outflows drain via two streams through the Wanhe Sluice to the Yangtze River.

Under the influence of the subtropical monsoon climate of the catchment, water level in the lake follows the typical pattern of summer flooding and winter drawdown, with a mean annual amplitude of $3.20 \mathrm{~m}$. The minimum water-level amplitude was $1.1 \mathrm{~m}$ in 1978 , while the maximum reached $6.01 \mathrm{~m}$ in 
1999, although the years 1977, 1980, 1983, 1995, 1996, 1998, 1999 and 2010 were also characterised by rather high water levels (see Fig. 2). Due to the major construction of levees to claim land, seasonally exposed areas are confined to the eastern lakeshores, where the expansion of emergent macrophytes originated. It should also be recognised that the sluicing of Wuchang Lake means that the water-level behaviour there now is very different to that of lakes that retain continuity with the Yangtze River (such as Poyang and Dongting Lakes). This means that major floods along the Yangtze River can have potentially little effect on water levels in Wuchang Lake, while Wuchang Lake experiences flooding and retain high water levels during relatively minor lesser flooding along the Yangtze (as was the case in 1998 and 1999 floods shown in Fig. 2, also see Ping et al. 2014).

Relatively few field botanical surveys have ever been conducted at Wuchang Lake, so there is limited information available from which to describe succession in vegetation communities at the site. The whole lake was used to be dominated by submerged macrophytes, and in 1985 the biomass of Potamogeton wrightii Morong reached about $1.64 \mathrm{~kg} / \mathrm{m}^{2}$ (Song 2003). By the 1990s, up to $85 \%$ of the Lower Lake surface was covered with macrophytes, dominated by submerged Vallisneria natans (Lour.) H.Hara and Hydrilla verticillata (L.f.) Royle and emergent $Z$. latifolia (Wang and Dou 1998). In the beginning of 2000s, Zhang and Zhu (2006) identified 8 macrophyte associations belonging to (1) submerged, (2) emergent and (3) floating communities, respectively. According to their surveys, (1) V. natans, (2) Z. latifolia, Nelumbo nucifera Gaertn., and (3) Trapa incise Siebold \& Zucc. were considered the dominant species in these communities.

Based on our summer surveys in 2010-2012, we found major differences in the macrophyte communities of Wuchang Upper and Lower Lakes as follows: (1) extensive areas of emergent plants dominated by $Z$. latifolia covered large areas of the Lower Lake with scattered distributions of floating and submerged plants, (2) macrophyte communities were scarce in the Upper Lake, (3) local residents confirmed the presence of Z. latifolia as the dominant emergent species in the Lower Lake since the 1970s. Notably, we witnessed that flooding in the summer of 2010 detached most of the standing crop of $Z$. latifolia from sediments and dead biomass of this species formed many large floating islands throughout the Lower Lake. These floating islands caused severe problems, as their movements, driven by wind and waves, blocked lake navigation.

\section{Satellite images selection and pre-processing}

Multispectral Scanner (MSS), Thematic Mapper (TM) and Enhanced Thematic Mapper Plus (ETM+) satellite images with a spatial resolution of $60 \mathrm{~m}$ for MSS data and $30 \mathrm{~m}$ for TM and ETM+ from 1975 to 2012 were used in this study (Table 1). We did not consider years after 2012 because management implemented by the fishing company post-2012 may have affected the extent of $Z$. latifolia in subsequent years. All the

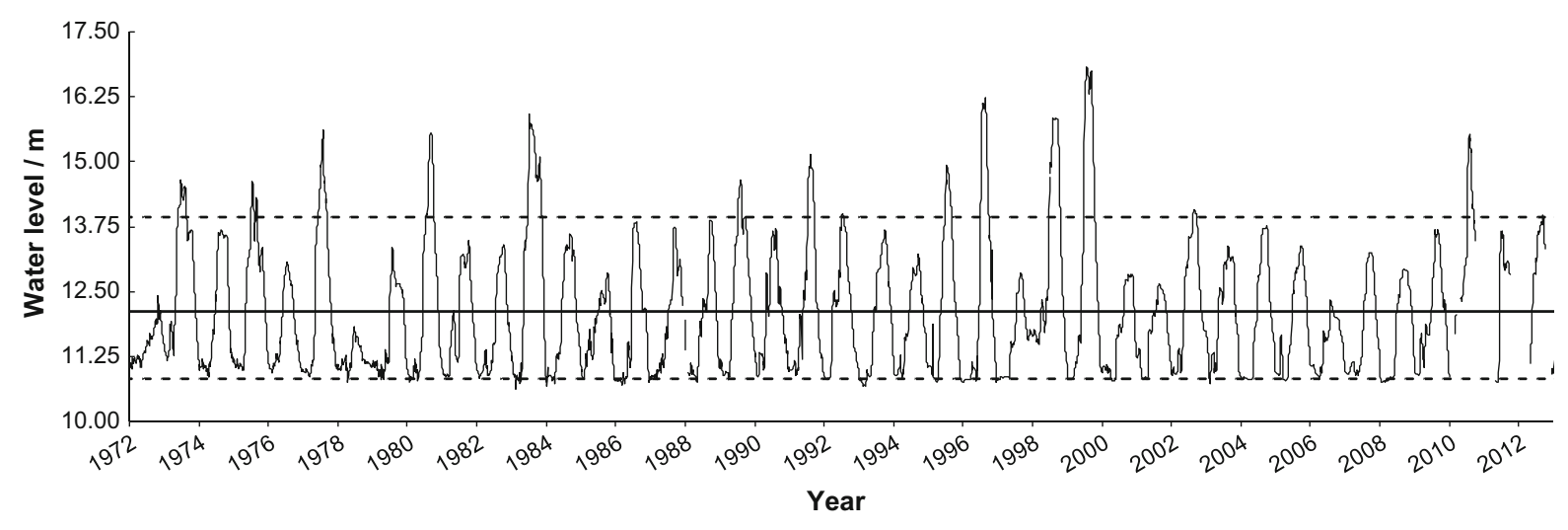

Fig. 2 Daily water level record of Wuchang Lake in Wuchang Station, which is located in Lower Lake. Solid line $(12.11 \mathrm{~m})$ in the middle is the mean water level. Upper dotted line $(13.93 \mathrm{~m})$ is the long-term averaged value of maximum water level, while lower $(10.81 \mathrm{~m})$ is the long-term averaged value of minimum water level 
Landsat images were downloaded from US Geology Survey site (http://glovis.usgs.gov). Images from Path 121 Row 39 in World Reference System were used for this study (see also Table 1). The density of aquatic macrophytes changes seasonally; thus, it is important to identify the period of maximum macrophyte abundance, which usually occurs at the site between July and September (Liira et al. 2010; Zhao et al. 2012). However, the number and quality of available images were not always satisfactory during the optimal survey period in some years, necessitating occasional use of images from June or October. Images with cloud cover less than $10 \%$ were selected and occasionally less than $30 \%$ were accepted (Kloiber et al. 2002), resulting in the final selection of 10 Landsat MSS and 15 Landsat TM and 8 ETM images (Table 1).

Hadjimitsis et al. (2004) recommend dark pixel correction to provide reasonable atmospheric correction over water compared to other more sophisticated methods (such as $6 \mathrm{~S}$ radiative transfer code). In this study, all images were processed with cosine correction of the sun zenith angle (COST) for atmospheric correction (Chavez Jr 1996).

Following this, satellite images were georeferenced using ground control points sampled in our field surveys. Geometric correction was applied using second-order polynomials with resampling method of cubic convolution. The accuracy of geocorrection was higher than 0.5 pixels.

Following artificial objects (levees or dams) and flooding water lines, we delineated the boundary of our study area based on images within Google Earth and a few georeferenced TM and ETM+ images. The boundary was then corrected according to our field survey records and used as a mask to remove external disturbances from terrestrial vegetation during subsequent classification.

Image processing steps

In order to discriminate between water and floating or emergent macrophytes (almost exclusively Z. latifolia based on our field observations), a supported vector machine (SVM) classification approach was followed. SVMs are supervised nonparametric statistical learning techniques and are preferentially used in remote sensing due to their ability to produce higher accuracy classifications with small training data sets (Mantero et al. 2005). Due to their efficiency and accuracy in binary classification (Boyd et al. 2006), we selected training sets visually from each image with the help of field survey records as pixels containing water or plants which were highly contrasting. Once defined, pixels were assigned to water or Z. latifolia within the defined edges of the wetland complex and were summed to define areas for the Upper and Lower Lakes separately.

Reference data (ground-truth data) are useful when assessing the accuracy of land cover classification (Kennedy et al. 2009). Many methods could be used to collect reference data such as sampling in situ data or using high-resolution satellite or aerial images (Biro et al. 2010). Due to the obvious difficulties in taking samples in the dense standing crops of Z. latifolia (see Fig. S1), we used high spatial resolution images in Google Earth as our reference data. Firstly, two IKONOS images are obtained from Google Earth to cover Wuchang Lake on 8 December 2008 and 9 March 2009. Then, two hundred points were randomly generated within each image, and we extracted
Table 1 Details of the satellite images of Wuchang Lakes used in this study, showing imagery date and type

resolution of MSS TM and ETM+ is 60, 30 and $30 \mathrm{~m}$, respectively

\begin{tabular}{llllllll}
\hline Date & Image & Date & Image & Date & Image & Date & Image \\
\hline $1975-06-08$ & MSS & $1984-09-03$ & MSS & $1997-09-07$ & TM & $2005-08-12$ & TM \\
$1976-06-20$ & MSS & $1987-06-08$ & TM & $1998-08-09$ & TM & $2006-07-30$ & TM \\
$1977-08-26$ & MSS & $1989-07-15$ & TM & $1999-09-29$ & TM & $2007-08-10$ & ETM+ \\
$1978-07-07$ & MSS & $1992-06-05$ & TM & $2000-07-05$ & ETM+ & $2008-07-27$ & ETM+ \\
$1979-08-07$ & MSS & $1993-06-08$ & TM & $2001-09-02$ & ETM+ & $2009-06-04$ & TM \\
$1980-09-24$ & MSS & $1994-08-30$ & TM & $2002-08-20$ & ETM+ & $2010-08-18$ & ETM+ \\
$1981-09-19$ & MSS & $1995-09-02$ & TM & $2003-07-30$ & ETM+ & $2011-07-28$ & TM \\
$1982-08-09$ & MSS & $1996-10-22$ & TM & $2004-08-09$ & TM & $2012-07-22$ & ETM+ \\
$1983-08-08$ & MSS & & & & & & \\
\hline
\end{tabular}


vegetation information visually for each point from IKONOS images as the reference data. A TM image at 10 December 2008 and an ETM+ image at 8 March 2009 were then processed using SVMs to yield classification maps. We built a confusion matrix to assess the classification accuracy based on reference data (see Table 2). The overall accuracies were $92.5 \%$ and $90.5 \%$, respectively, for the classifications of the TM and ETM+ image. These results suggested that our method could be used effectively for our classification purpose (see Table 2).

Fluorescence line height (FLH) is regarded as a useful index in trophic status assessment, as it can be related to chlorophyll-a concentration ( $\mathrm{Hu} 2009$; Huang et al. 2014). In this study, we used FLH to assess trophic status, and following the method of Huang et al. (2014), FLH was calculated from Landsat images as followed:

$\mathrm{FLH}=L_{\lambda 2}-\left(L_{\lambda 1}+\left(L_{\lambda 3}-L_{\lambda 1}\right) \frac{\lambda 2-\lambda 1}{\lambda 3-\lambda 1}\right)$

where $L$ is the radiance corrected by improved COST; for MSS, $\lambda 1=650 \mathrm{~nm}, \lambda 2=750 \mathrm{~nm}, \lambda 3=950 \mathrm{~nm}$; for TM and ETM $+, \lambda 1=660 \mathrm{~nm}, \lambda 2=830 \mathrm{~nm}$ and $\lambda 3=1650 \mathrm{~nm}$. Correlation between FLH and chlorophyll-a concentration was tested based on field surveys of several lakes in Anhui in 2008 from the China Lake Scientific Data Sharing Platform for Lakes and Watersheds (http://www.lakesci.csdb.cn). Results showed that FLH was significantly correlated with

Table 2 Matrix of classification accuracy based on 200 random points sampled within a TM image from 10 December 2008 and an ETM+ image at 8 March 2009 compared to the reference data

\begin{tabular}{lccrl}
\hline Reference & \multicolumn{3}{c}{ Total } & User $(\%)$ \\
\cline { 1 - 2 } Classified & Vegetation & Open water & & \\
\cline { 1 - 4 } $2008-12$ & & & 33 & 72.7 \\
Vegetation & 24 & 9 & 167 & 96.4 \\
Open water & 6 & 161 & 200 & 92.5 \\
Total & 30 & 170 & & \\
Producer (\%) & 80.0 & 94.7 & & \\
2009-3 & & & 145 & 95.2 \\
Vegetation & 138 & 7 & 55 & 78.2 \\
Open water & 12 & 43 & 200 & 90.5 \\
Total & 150 & 50 & & \\
Producer $(\%)$ & 92.0 & 86.0 & & \\
\hline
\end{tabular}

chlorophyll-a $\left(r^{2}=0.61, P \ll 0.01, n=40\right)$, so following this average FLH values were retrieved from water pixels identified by SVMs.

However, submerged macrophytes could also potentially form a dense reflecting canopy during the growing season (April to October), which might contribute to FLH values due to its sensitivity to changes in chlorophyll abundance at the water surface. We used data from our field surveys to compare FLH values of pixels with and without dense growth of submerged macrophytes in 2011, as few submerged macrophytes were sampled in 2010 and 2012. The difference between the means was statistically significant $(P<0.05$, pixels without submerged macrophyte $n=85$; pixels with submerged macrophyte, $n=23$ ) but acceptable: The averaged FLH value of pixels from open water without and with submerged macrophyte was -7.41 and -6.03 , respectively, which suggests that the contribution of submerged macrophyte to FLH might not be decisive, considering the much larger range of FLH values $(-21.17$ to -9.52$)$ between years.

\section{Data analysis}

Due to the shallow distribution of its underground biomass, after extreme flood events, detached and fragmented Z. latifolia would be floating (Tsuchiya et al. 1993), making it difficult to estimate the true in situ distribution from remote sensing images. We therefore excluded years when this may affect our assessment of the extent of $Z$. latifolia based on the following criteria: (1) years when the water level during flooding season reached $14 \mathrm{~m}$ or more (averaged maximum water level during 1975-2012 is $13.92 \mathrm{~m}$ ); (2) when the acquisition date of the imagery was later than the date of highest water level. On this basis, data from 1977, 1980, 1983, 1995, 1996, 1998, 1999 and 2010 were excluded from our data set prior to modelling. Daily water level data during 1975-2012 was provided by the Anqing Hydrology Bureau based on Wusong Datum. Daily water level was averaged to derive seasonal measures (SeptemberNovember: autumn; December-February: winter; March-May: spring; June-August: summer) to avoid multicollinearity between variables.

We applied generalised additive models (GAMs) to analyse the effects of annual water level in different seasons and trophic status on the expansion area of $Z$. latifolia through the time series in the Lower Lake. Areas of Z. latifolia were log-transformed and fitted 
using Gaussian distributed error terms and a log link. As the aboveground biomass of Z. latifolia would stop increasing before September (Asaeda and Siong 2008), autumn (September to November) and winter (December to February) water level would most likely affect growth in the following year. Therefore, year, autumn and winter water levels in the preceding year, spring and summer water level and FLH were entered as smoothers taking up to four degrees of freedom. We used cubic regression spline smoothing to produce the most robust model structure (Wood 2008). GAMs were built using the "mgcv" package (Wood and Wood 2016) in R (R Development Core Team 2014), and we followed a model selection procedure based on the corrected Akaike's information criteria (AICc) to get the best models with $\triangle \mathrm{AICc}<2$ using the "MuMIn" package (Barton 2013) in R. Variance inflation factors (VIFs) were all less than 4, suggesting that multicollinearity could be ignored (O'brien 2007).

\section{Results}

Temporal and spatial dynamics of Z. latifolia distributions

In the early summer of 1975 , a total area of $12.50 \mathrm{~km}^{2}$ of Z. latifolia was found, primarily restricted to the eastern part of the Lower Lake. From that time onwards, Z. latifolia expanded gradually to cover most of the Lower Lake from 2000 onwards (see Fig. 3). The area covered by Z. latifolia in the Lower Lake ranged from a minimum of $9.68 \mathrm{~km}^{2}$ (1992) to a maximum of $49.17 \mathrm{~km}^{2}$ (2001, average $28.32 \mathrm{~km}^{2}$, see Fig. 4). In the Upper Lake, Z. latifolia was confined to the inlet of a river (see Fig. 3) varying in area from a minimum of $0.28 \mathrm{~km}^{2}$ (1989) to a maximum of $3.33 \mathrm{~km}^{2}$ (1978, average $1.06 \mathrm{~km}^{2}$, see Fig. 4).

\section{Analysis of expansion}

Comparison of AICc and $\triangle \mathrm{AICc}$ values showed that the best GAM incorporated year and spring water level, which explained $93.8 \%$ of the deviance in log-transformed Z. latifolia area (see Supplemental Information, Table S1). Both year (edf $=2.902, P \ll 0.01)$ and spring water level (edf $=2.091, P<0.01$ ) contributed significantly to the models. Annually, the extent of the area of Z. latifolia increased slowly in the late 1970s and early 1980s. Afterwards, it rose dramatically during 1990 s and peaked in the early 2000s. In recent years, the coverage of $Z$. latifolia has tended to shrink back slightly (Fig. 5a). Annually the extent of the Z. latifolia area declined as spring water level increased (Fig. 5b), and the rate of decrease was more rapid when water levels rose above $11.6 \mathrm{~m}$.

However, we ignored the effects of very extreme flooding events, which were deliberately excluded from our analysis. Such events eliminated most of the visible biomass on the water surface and remnant submerged vegetation making it impossible to effectively establish the area of Z. latifolia from remote sensing data (like in 1977, 1983, 1996, 1999, 2010, see Fig. 3). In spite of such catastrophic years, Z. latifolia seems able to rehabilitate following such years, sometimes showing expansions in coverage in the subsequent years (i.e. 2009, 2010 and 2011, see Fig. 3).

\section{Discussion}

Our results clearly showed a gradual loss of open water in Lower Wuchang Lake due to the encroachment from Z. latifolia during 1975 to 2012, but not in the form of simple incremental development. Large between-year differences in the extent of Z. latifolia, based on remote sensing, bear witness to this not being a progressive encroachment achieved by gradual annual expansion from initial points of colonisation. This fact was further confirmed by the results of the best GAM, showing that the variation in area was negatively affected by spring lake water level, such that springs with consistently high water levels resulted in reduced summer cover. This gives some hope for the application of hydrological management, which could be used to manipulate the extent of cover of this plant in the future (see below).

Zizania latifolia is a common and widespread wetland species in south-eastern China. It is cultivated or exploited in the wild as a source of food and forage for domestic stock throughout the Yangtze River floodplain. Compared to another emergent species, such as Phragmites australis (Cav.) Trin. ex Steud., Z. latifolia has been the subject of less concern within its native range in relation to its threats to other aquatic organisms (but see Yamasaki 1984; Asaeda and Siong 

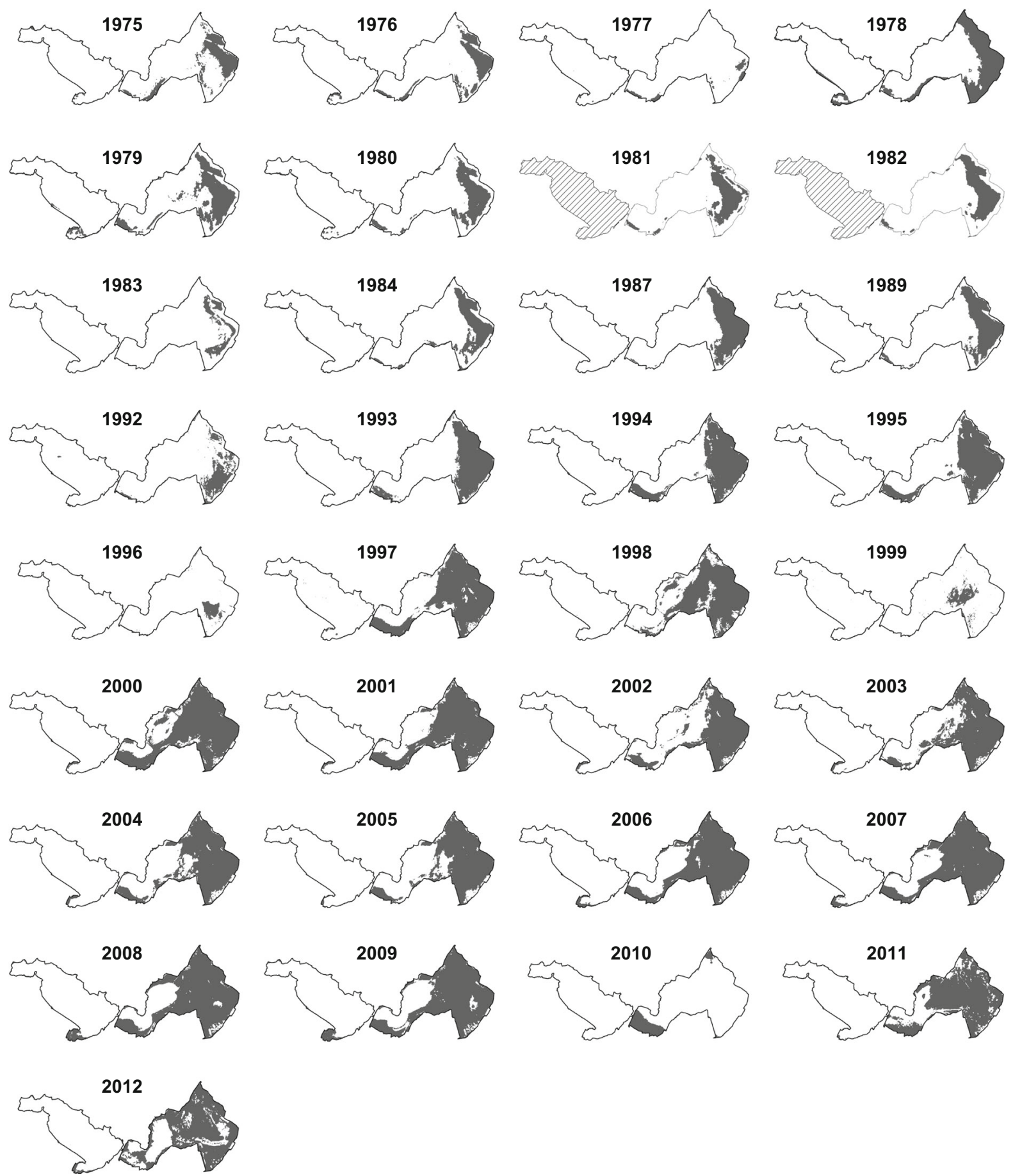

Fig. 3 Distribution of Z. latifolia (dark area) between 1975 and 2012. Cross-hatched area indicates no imagery data were available for this area in that year

2008), although it has been identified as a problem invasive alien species in New Zealand and elsewhere (Auckland Regional Council 2002; Gobal Invasive
Species Database 2016). However, the recent cases of rapid and massive expansions of the species at East Taihu Lake (Li 1996) and in the present study at 
Fig. 4 Temporal trends (1975-2012) in the extent of Z. latifolia in Upper Lake and Lower Lakes
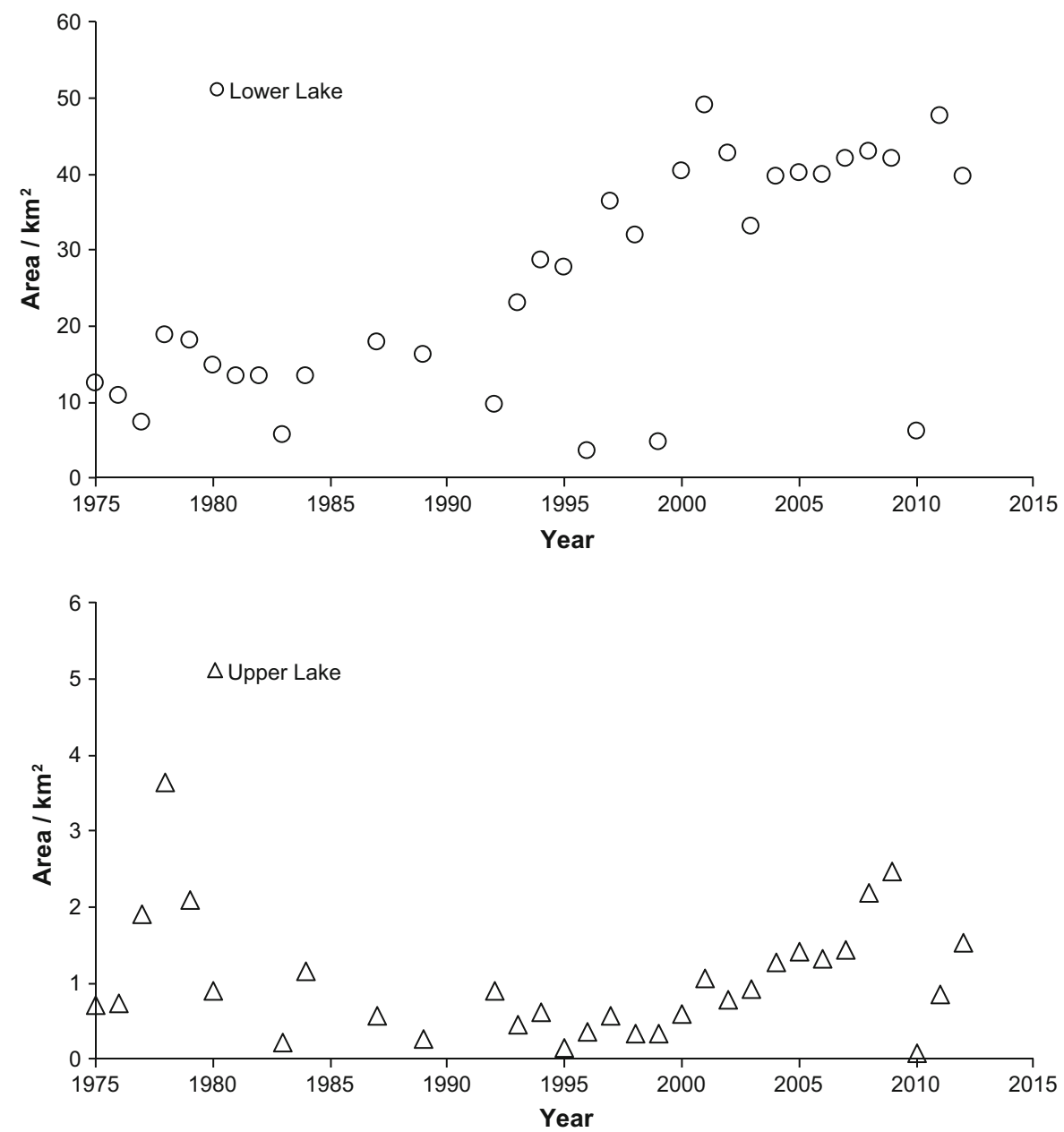

Wuchang Lower Lake show that the species can threaten the biota, ecosystem services and open water integrity of large lakes, which underline the need for further studies on Z. latifolia.

\section{Temporal changes and potential drivers}

In this study, we used medium-resolution satellite images to determine the change in temporal extent of Z. latifolia and found that, while there were hardly any changes in total coverage on the Upper Lake, dramatic inter-annual changes in Z. latifolia area characterised the Lower Lake in recent decades. We used GAMs to analyse the effect of year, water level and trophic status on Z. latifolia area and found that (1) in general, the area of Z. latifolia increased during 1975-2012 but with contrasting variations between years, and (2) variation of water level in spring seemed to contribute to such differences, whereby high spring water levels hampered the expansion of Z. latifolia. Compared to Zhang et al. (2016), our results demonstrated a more complex pattern of nonlinear expansion in extent of $Z$. latifolia and showed the evident importance of spring water level using robust statistical analysis.

Trophic status is regarded as an important driver of the expansion in aquatic macrophytes worldwide (Scheffer et al. 2001). Previous studies have indicated that the biomass of emergent macrophytes would increase with the trophic status of the lake (see Malthus et al. 1990). However, in our study, the nutrient quality of the shared water in the two basins does not differ much, so changes in water quality, which will affect both parts of the lake, are not likely to be a major contribution to explain the differences in vegetation dynamics. Zhao et al. (2012) postulated that such effects might be more profound at longer temporal scales ( $>10$ years) than to shorter 
Fig. 5 Effect of cubic regression spline smoothed $(s)$ year (a) and averaged spring (March to May) water level (b) on log-transformed area of $Z$. latifolia, as fitted by a GAM. Dotted lines showed the bounds of the $95 \%$ C.I. The unit of water level is metre

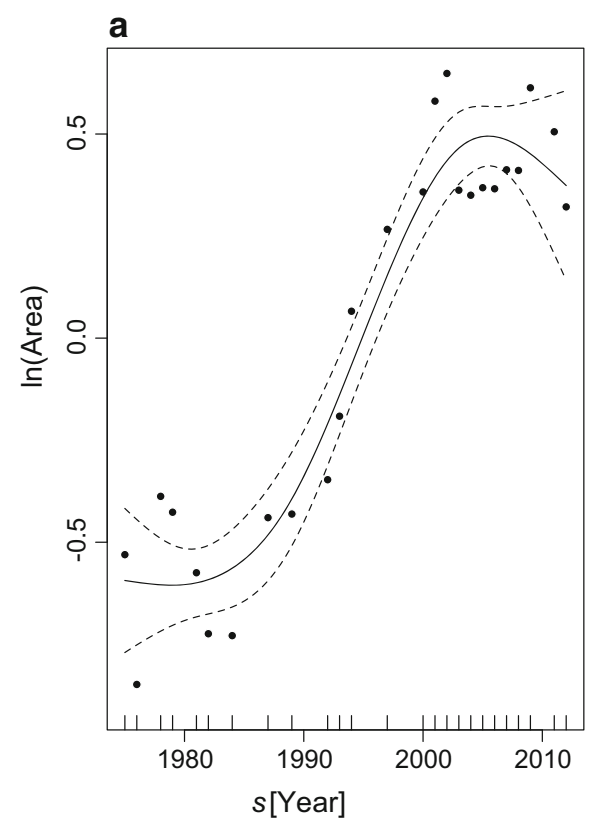

temporal scales (i.e. 1-2 years), which could explain the absence of FLH as a variable contributing to the best-fit GAMs.

Spring (March-May) is the time of the initial growth of Z. latifolia and is regarded as the key stage during its annual life history (Tsuchiya et al. 1993; Asaeda and Siong 2008). Higher density of shoots, earlier emergence and photosynthesis on the one hand enable Z. latifolia to be less reliant upon belowground rhizomes and to outgrow other macrophytes (Asaeda and Siong 2008). On the other hand, these characters weaken its tolerance to water stress at this stage when there is less energy available for shoots to develop and to initiate photosynthesis (Asaeda and Siong 2008). Nevertheless, excessive summer flooding can also exert a profound effect on the aboveground biomass of Z. latifolia, which will be washed away during such periods of high water (Tsuchiya et al. 1993 and as witnessed at Lower Wuchang Lake in 2010). However, Z. latifolia seems to recover rapidly in years following extreme flood events at Wuchang Lake, sometimes apparently expanding faster under such circumstances. This might be explained by much reduced water levels in the following years (see the patterns of water levels recorded in 1978, 1984, 1997, 2000 and 2011, Fig. 3), which would favour rehabilitation by Z. latifolia.

\section{Differences between Upper and Lower Lakes}

Our results showed dramatic differences in aquatic macrophytes between the Upper and Lower Wuchang Lakes, which might be attributed to differences between the water regime management of the two lakes.

The dam separating Upper Lake and Lower Lake was built to enhance fishing activities and is one of the key factors responsible for such differences. The dam does not function until the water table falls below its level (the top of dam is estimated to be $13.37 \mathrm{~m}$ above sea level), when levels in the Upper Lake remain above (normally about $1 \mathrm{~m}$ during October-April) that in the Lower Lake. Our results suggest that such a marginally higher water level in spring and autumn in the Upper Lake is enough to inhibit the growth and expansion of $Z$. latifolia, which is present but never develops to any large extent. The geomorphology of lake bottom may also play an important role, as it will affect distribution of macrophytes as a result of depth gradients (Sculthorpe 1967), but given that the lake bed elevation of Upper Lake is on average around $0.7 \mathrm{~m}$ lower than that of the Lower Lake, the combined effect of lower elevation and higher water level in spring and autumn is responsible for the contrasting vegetation successions witnessed in the Upper and Lower Lakes. 
Management recommendations

In this study, we used remote sensing to demonstrate a dramatic increase in the extent of $Z$. latifolia over a time scale of decades. This development has reduced the area of open water available for aquaculture for local communities, which have consequently suffered financial losses from major reductions in fishing income. Hence, there is a considerable social and economic need for future management actions to restore open water and more favoured submerged macrophyte communities to Wuchang Lake as a whole if possible.

Zizania latifolia is difficult to eliminate by physical removal by virtue of the extremely large annual accumulation of biomass and because any root or rhizome fragments are robust and quickly re-grow (Auckland Regional Council 2002). Herbicides might contribute to effective control, but clearly the use of herbicide in wetland systems and lakes associated with food production creates challenges for the food supply and may be restricted under law as well necessitating follow-up remedial treatments (Biosecurity New Zealand 2006). Our results showed that increased water levels in spring (March-May) correlated with reduced expansion in Z. latifolia area, which suggests that raising water levels during such periods could be successful in reducing the area colonised by this plant. Such an approach would avoid any need to resort to control chemicals and herbicides, although expensive cutting and removal of biomass could potentially provide additional means of reducing biomass. Chandra and Tanaka (2006) identified two key seasons when cutting and removal of $Z$. latifolia shoots may be effective in control: one during the period when substantial self-thinning of shoots occurs (June-July, see Tsuchiya et al. 1993) and the other when the plant is mature before senescence (September-October, see also Tsuchiya et al. 1993). Although labour intensive and costly, such measures could potentially provide an additional means of controlling biomass accumulation of Z. latifolia at this site. Thus, to improve lake management and elevate the provision of ecosystem services, we advocate raising of water levels in the Lower Lake in spring to be above at least at $11.6 \mathrm{~m}$ and better at $12 \mathrm{~m}$ (averaged $11.28 \mathrm{~m}$ during 1975-2012) followed by cutting of shoots in June and July, followed by continued removal of shoots in autumn if this is possible.
Future monitoring in application

In this research, we demonstrated that the Landsat image archive, which provided us with 40 years of historical data, could be a powerful and efficient technique to track rapid changes in aquatic ecosystems. Furthermore, we propose to continue monitoring the distribution of $Z$. latifolia in the Lower Lake by utilising a new generation of remote sensing images to guide the management efforts as well as to appraise the effects of certain managements in future years. Such methods could be used to track the distribution dynamics of other "visible" macrophytes, such as floating Trapa spp., emergent Phragmites australis, and sometimes the less visible biomass of submerged Vallesnaria spp. or Potamogeton spp., and further help local communities to optimise sustainable lake management interventions.

Compared to Landsat ETM+ and OLI images (which offer 16-day temporal resolution), the Chinese HJ-1 and the European Sentinel-2, both of which are openly and freely accessible to worldwide researchers now, seem to be more appropriate remote sensing tools to monitor wetland vegetation life history and areal change because of their more frequent 2-day and 5-day revisit times, respectively.

Acknowledgements This study was supported by the National Key Technology R\&D Program (2015BAD13B01), the National Natural Science Foundation of China (Grant No. 31370416), State Key Laboratory of Urban and Regional Ecology, Chinese Academy of Sciences (No. SKLURE2013-1-05), China Biodiversity Observation Networks (Sino BON) as well as ESA MOST DRAGON 3 project 10577 and "Synergy of Satellite Imagery and Altimetry for Inland Water Bodies and Wetland Monitoring. Applications to the Analysis of Water Resource Dynamic in Terms of Risk Management, Water Quality, Biodiversity Dynamic trends and Public Health”.

\section{References}

Andersson B (2001) Macrophyte development and habitat characteristics in Sweden's large lakes. Ambio 30:503-513. doi:10.1579/0044-7447-30.8.503

Asaeda T, Siong K (2008) Dynamics of growth, carbon and nutrient translocation in Zizania latifolia. Ecol Eng 32:156-165. doi:10.1016/j.ecoleng.2007.10.005

Auckland Regional Council (2002) Auckland regional pest management strategy. Auckland Regional Council, Auckland

Barter M, Cao L, Chen L, Lei G (2005) Results of a survey for waterbirds in the lower Yangtze floodplain, China, in January-February 2004. Forktail 21:1 
Barton K (2013) MuMIn: multi-model inference. R package version 1.9. 5

Barzen J, Engels M, Burnham J, Harris J, Wu G (2009) Potential impacts of a water control structure on the abundance and distribution of wintering waterbirds at Poyang Lake. Unpublished report submitted to Hydro-Ecology Institute of the Yangtze Water Resources Commission Baraboo. International Crane Foundation, Wisconsin

Biosecurity New Zealand (2006) National pest plant accord. Ministry of Agriculture and Forestry, Wellington

Biro K, Pradhan B, Buchroithner M, Makeschin F (2010) Use of multi-temporal satellite data for land-use/land-cover change analyses and its impacts on soil properties in the northern part of Gadarif Region. In: Reuter R (ed) Remote sensing for science, education and natural and cultural heritage. EARSel, Paris, pp 305-312

Boyd DS, Sanchez-Hernandez C, Foody GM (2006) Mapping a specific class for priority habitats monitoring from satellite sensor data. Int J Remote Sens 27:2631-2644. doi:10.1080/ 01431160600554348

Brivio PA, Giardino C, Zilioli E (2001) Validation of satellite data for quality assurance in lake monitoring applications. Sci Total Environ 268:3-18. doi:10.1016/S0048-9697(00) 00693-8

Cao L, Fox AD (2009) Birds and people both depend on China's wetlands. Nature 460:173. doi:10.1038/460173b

Cao L, Zhang Y, Barter M, Lei G (2010) Anatidae in eastern China during the non-breeding season: geographical distributions and protection status. Biol Conserv 143:650659. doi:10.1016/j.biocon.2009.12.001

Chandra DS, Tanaka N (2006) Harvesting aerial shoots of Zizania latifolia at different growth stages: effects on belowground biomass, regrowth, and rhizome morphology. J Freshw Ecol 21:583-591. doi:10.1080/02705060. 2006.9664119

Chavez P Jr (1996) Image-based atmospheric corrections-revisited and revised. Photogramm Eng Remote Sens 62: 1025-1036

Development Core Team R (2014) R: a language and environment for statistical computing. R Foundation for Statistical Computing, Vienna

Engloner AI (2009) Structure, growth dynamics and biomass of reed (Phragmites australis) - a review. Flora Morphol Distrib Funct Ecol Plants 204:331-346. doi:10.1016/j. flora.2008.05.001

Fang J, Wang Z, Zhao S, Li Y, Tang Z, Yu D, Ni L, Liu H, Xie P, Da L (2006) Biodiversity changes in the lakes of the Central Yangtze. Front Ecol Environ 4:369-377. doi:10. 1890/1540-9295(2006)004[0369:BCITLO]2.0.CO;2

Fox AD, Cao L, Zhang Y, Barter M, Zhao MJ, Meng FJ, Wang SL (2011) Declines in the tuber-feeding waterbird guild at Shengjin Lake National Nature Reserve, China-a barometer of submerged macrophyte collapse. Aquat Conserv 21:82-91. doi:10.1002/aqc.1154

Gobal Invasive Species Database (2016) Species profile: Zizania latifolia. http://www.iucngisd.org/gisd/species.php?sc $=866$ on 10 July 2016

Hadjimitsis D, Clayton C, Hope V (2004) An assessment of the effectiveness of atmospheric correction algorithms through the remote sensing of some reservoirs. Int J Remote Sens 25:3651-3674. doi:10.1080/01431160310001647993
Harris J, Zhuang H (2010) An ecosystem approach to resolving conflicts among ecological and economic priorities for Poyang Lake wetlands. Unpublished report IUCN, Gland

$\mathrm{Hu} \mathrm{C}$ (2009) A novel ocean color index to detect floating algae in the global oceans. Remote Sens Environ 113:21182129. doi:10.1016/j.rse.2009.05.012

Huang C, Wang X, Yang H, Li Y, Wang Y, Chen X, Xu L (2014) Satellite data regarding the eutrophication response to human activities in the plateau lake Dianchi in China from 1974 to 2009. Sci Total Environ 485:1-11. doi:10.1016/j. scitotenv.2014.03.031

Jackson JB, Kirby MX, Berger WH, Bjorndal KA, Botsford LW, Bourque BJ, Bradbury RH, Cooke R, Erlandson J, Estes JA (2001) Historical overfishing and the recent collapse of coastal ecosystems. Science 293:629-637. doi:10.1126/ science. 1059199

Kennedy RE, Townsend PA, Gross JE, Cohen WB, Bolstad P, Wang YQ, Adams P (2009) Remote sensing change detection tools for natural resource managers: understanding concepts and tradeoffs in the design of landscape monitoring projects. Remote Sens Environ 113:13821396. doi:10.1016/j.rse.2008.07.018

Kloiber SM, Brezonik PL, Olmanson LG, Bauer ME (2002) A procedure for regional lake water clarity assessment using Landsat multispectral data. Remote Sens Environ 82: 38-47. doi:10.1016/S0034-4257(02)00022-6

Kühl H, Zemlin R (2000) Increasing the efficiency of reed plantations on stressed lake and river shores by using special clones of Phragmites australis. Wetl Ecol Manag 8:415-424. doi:10.1023/A:1026510018318

Lampert W, Sommer U (2007) Limnoecology: the ecology of lakes and streams. University Press, Oxford

Lei G (1999) Status of the lesser white-fronted goose in China. Fennoscandian lesser white-fronted goose conservation project annual report, pp 16-17

Li W (1996) Yellow water in East Taihu Lake caused by Zizania latifolia and its prevention. J Lake Sci 9:364-368

Liira J, Feldmann T, Mäemets H, Peterson U (2010) Two decades of macrophyte expansion on the shores of a large shallow northern temperate lake-a retrospective series of satellite images. Aquat Bot 93:207-215. doi:10.1016/j. aquabot.2010.08.001

Malthus T, Best E, Dekker A (1990) An assessment of the importance of emergent and floating-leaved macrophytes to trophic status in the Loosdrecht lakes (The Netherlands). Hydrobiologia 191:257-263. doi:10.1007/BF00026060

Mantero P, Moser G, Serpico SB (2005) Partially supervised classification of remote sensing images through SVMbased probability density estimation. IEEE Trans Geosci Remote 43:559-570. doi:10.1109/TGRS.2004.842022

Nelson SA, Cheruvelil KS, Soranno PA (2006) Satellite remote sensing of freshwater macrophytes and the influence of water clarity. Aquat Bot 85:289-298. doi:10.1109/TGRS. 2004.842022

O'brien RM (2007) A caution regarding rules of thumb for variance inflation factors. Qual Quant 41:673-690. doi:10. 1007/s11135-006-9018-6

Olmanson LG, Bauer ME, Brezonik PL (2008) A 20-year Landsat water clarity census of Minnesota's 10,000 lakes. Remote Sens Environ 112:4086-4097. doi:10.1016/j.rse. 2007.12.013 
Orth RJ, Moore KA (1983) Chesapeake Bay: an unprecedented decline in submerged aquatic vegetation. Science (Washington) 222:51-53

Partanen S, Hellsten S (2005) Changes of emergent aquatic macrophyte cover in seven large boreal lakes in Finland with special reference to water level regulation. Fennia Int J Geogr 183:57-79

Ping F, Tang X, Gao S, Luo Z (2014) A comparative study of the atmospheric circulations associated with rainy-season floods between the Yangtze and Huaihe River Basins. Sci China Ser D 57:1464-1479. doi:10.1007/s11430-013-4802-3

Rannap R, Lõhmus A, Jakobson K (2007) Consequences of coastal meadow degradation: the case of the natterjack toad (Bufo calamita) in Estonia. Wetlands 27:390-398. doi:10. 1672/0277-5212(2007)27[390:COCMDT]2.0.CO;2

Rørslett B (1991) Principal determinants of aquatic macrophyte richness in northern European lakes. Aquat Bot 39:173193. doi:10.1016/0304-3770(91)90031-Y

Scheffer M (2004) The story of some shallow lakes. Ecology of Shallow Lakes. Springer, The Netherlands, pp 1-19. doi:10.1007/978-1-4020-3154-0_1

Scheffer M, Carpenter S, Foley JA, Folke C, Walker B (2001) Catastrophic shifts in ecosystems. Nature 413:591-596. doi: $10.1038 / 35098000$

Scheffer M, Szabo S, Gragnani A, Van Nes EH, Rinaldi S, Kautsky N, Norberg J, Roijackers RM, Franken RJ (2003) Floating plant dominance as a stable state. Proc Natl Acad Sci USA 100:4040-4045. doi:10.1073/pnas.0737918100

Sculthorpe CD (1967) Biology of aquatic vascular plants. St. Martin's, New York

Song L (2003) A study on fishery resources of Wuchang Lake and corresponding comprehensive exploiting countermeasures. Territ Nat Resour Study 2:003
Tsuchiya T, Shinozuka A, Ikusima I (1993) Population dynamics, productivity and biomass allocation of Zizania latifolia in an aquatic-terrestrial ecotone. Ecol Res 8:193-198. doi:10.1007/BF02348532

van der Heide T, van Nes EH, van Katwijk MM, Olff H, Smolders AJ (2011) Positive feedbacks in seagrass ecosystems-evidence from large-scale empirical data. PLoS ONE 6:e16504. doi:10.1371/journal.pone.0016504

Wang SM, Dou HS (1998) Lakes in China. Science Press, Beijing

Wangjiang County Compilation Committee (1995) Wangjiang County Annals. Huangshan Publishing House, Huangshan

Wood SN (2008) Fast stable direct fitting and smoothness selection for generalized additive models. J Roy Stat Soc B 70:495-518. doi:10.1111/j.1467-9868.2007.00646.x

Wood S, Wood MS (2016) Package 'mgcv'. R package version: 1.7-29

Yamasaki S (1984) Role of plant aeration in zonation of Zizania latifolia and Phragmites australis. Aquat Bot 18:287-297. doi:10.1016/0304-3770(84)90070-6

Zhang S, Zhu H (2006) Preliminary surveys of wetland vegetation in Wuchang Lake. Anhui Agric Sci Bull 11:97

Zhang X, Wan A, Wang H, Zhu L, Yin J, Liu Z, Yu D (2016) The overgrowth of Zizania latifolia in a subtropical floodplain lake: changes in its distribution and possible water level control measures. Ecol Eng 89:114-120. doi:10.1016/j.ecoleng.2016.01.069

Zhao D, Jiang H, Cai Y, An S (2012) Artificial regulation of water level and its effect on aquatic macrophyte distribution in Taihu Lake. PLoS ONE 7:e44836. doi:10.1371/ journal.pone.0044836 